DOI: 10.20472/IAC.2018.935.050

\author{
RANDY TUDY \\ Cor Jesu College, Philippines
}

\title{
EARNING WHILE WORKING FROM HOME: A NEW EMPLOYMENT OPPORTUNITY IN THE PHILIPPINES
}

\begin{abstract}
:
Unemployment is global phenomenon even among advanced countries. The phenomenon of people working from home is gaining interest for many people, especially those still looking for jobs. The main purpose of this study was to explore on the work experiences of people working from home or the virtual professionals. This study employed a qualitative research design using phenomenological tradition. Twelve participants from different parts of the Philippines willingly responded to the Key Informant Interviews (KII). In terms of how the participants described their life, including the advantages, the findings revealed the following themes: Freedom, Flexibility, Family Time, Learning Experience, Convenience and Financial Advantage. As to the challenges they experienced, Internet Interruption, Distractions, and Less Social Life were the three major themes that came out. For their suggestions to those still looking for jobs, three themes emerged: Online Work, Confidence and Skills Development. The participants were happy with their work, giving the fact that they have more time with their family and enjoy other benefits. The findings of the study were sources of inspiration for those who are still jobless, for parents who want to be with their kids, but still earn a living, and even for people with disabilities (PWD). Indeed, without much government intervention and investment, the virtual professionals are finding jobs and are paving the way for combating unemployment. The implication of the study is for government and other agencies to understand this new phenomenon and to create mechanisms to support and promote it.
\end{abstract}

\section{Keywords:}

Economics, Work from home, Virtual Professionals, Employment, Phenomenology, Philippines

JEL Classification: A10, 015, E24 